\title{
Revival of an old stressor: Dobutamine- stimulation for PET myocardial perfusion imaging in patients with end-stage liver disease?
}

\author{
Thomas H. Schindler, MD, PhD, ${ }^{\mathrm{a}}$ and Thorsten Leucker, $\mathrm{MD}^{\mathrm{b}}$ \\ a Division of Nuclear Medicine, Mallinckrodt Institute of Radiology, Washington University \\ School of Medicine, St. Louis, MO \\ b Division of Cardiology, Department of Medicine, Johns Hopkins University, Baltimore, MD
}

Received Nov 20, 2018; accepted Nov 20, 2018

doi: $10.1007 / \mathrm{s} 12350-018-01543-5$

See related article, pp. 2048-2059

In patients with end-stage liver disease (ESLD), the exclusion of hemodynamically obstructive coronary artery disease (CAD) and normal left ventricular function with e.g., stress-rest scintigraphic myocardial perfusion imaging (MPI) commonly constitutes a pre-requisite to be listed for liver transplantation. ${ }^{1,2}$ An indeed, perioperative risk and clinical outcome may be affected by the CAD process in liver transplant recipients. ${ }^{2}$ Most ESLD patients may not be able to sufficiently exercise on the treadmill to reach $85 \%$ of predicted maximal heart rate and/or more than 5 METS for a sufficient diagnostic yield with MPI. ${ }^{3,4}$ In such patients, pharmacologic stress testing with either vasodilator stress such as with regadenoson, dipyridamole, or adenosine, or with $\beta 1$ stimulated increase in heart rate and contractility by dobutamine remain viable options to induce hyperemic myocardial blood flow (MBF) increases. ${ }^{5}$ The mechanism of these pharmacologic agents to stimulate hyperemic MBFs are distinct different. For example, pharmacologic vasodilation of the coronary arteriolar resistance vessels with regadenoson will lead to submaximal or maximal hyperemic flow increases uncoupled from the metabolic demand of the left ventricle. ${ }^{6}$ In the presence of flow-limiting CAD lesions, relative

\footnotetext{
Reprint requests: Thomas H. Schindler, MD, PhD, Division of Nuclear Medicine, Mallinckrodt Institute of Radiology, Washington University School of Medicine, 1510 S. Kingshighway, St. Louis, MO 63110; thomas.h.schindler@gmail.com

J Nucl Cardiol 2020;27:2060-2.

$1071-3581 / \$ 34.00$

Copyright (c) 2018 American Society of Nuclear Cardiology.
}

differences in radiotracer uptake or perfusion heterogeneity can be noted as the hyperemic MBF increases in the myocardial region subtended by an obstructive $\mathrm{CAD}$ lesion will be less than in the remote myocardial region without significant coronary obstruction. ${ }^{7,8}$ Such observed differences in regional radiotracer uptake is a sensitive approach for the identification of flow-limiting CAD burden but it may not necessarily cause classical ischemia as evidenced by corresponding wall motion abnormalities. ${ }^{9}$ Conversely, dobutamine-stimulation with increases in heart rate and contractility increase MBFs indirectly by elevations in myocardial metabolic and thus oxygen demand leading to a metabolically mediated vasodilation of the coronary microcirculation. Consequently, impaired coronary flow increases in response to dobutamine-stimulation due to a flow-limiting epicardial lesion is more likely to cause a perfusion deficit associated with classical ischemia induced wall motion abnormality or myocardial stunning due to a mismatch between increased metabolic demand and insufficient oxygen supply. Given these mechanistic differences in pharmacologic induced hyperemic MBF increases among vasodilator-and dobutamine stressors, cardiac PET flow studies revealed distinct higher hyperemic MBF values with pharmacologic vasodilation of the coronary arteriolar vessels than with dobutaminestimulation. ${ }^{10-12}$ For example, Jagathesan et al. ${ }^{5}$ reported of hyperemic MBF increases and MFR in the normal range, as determined with ${ }^{15} \mathrm{O}$-water PET, but significantly higher for flow increase stimulation with the vasodilator adenosine than with dobutamine (hyperemic MBFs: $4.04 \pm 0.51$ vs $3.18 \pm 0.96 \mathrm{ml} / \mathrm{g} / \mathrm{min}$ and MFR: $3.36 \pm 0.48$ vs $2.62 \pm 0.57 ; P<0.05$, respectively). Such observations may provide a rationale for the commonly observed higher sensitivities of pharmacologic 
vasodilator versus dobutamine stress scintigraphic MPI, while dobutamine stress stimulation afforded a higher specificity in CAD detection and characterization. ${ }^{13,14}$

In this issue of the Journal of Nuclear Cardiology, Abele et al. ${ }^{15}$ report of hyperemic MBF and myocardial flow reserve $(\mathrm{MFR}=$ hyperemic $\mathrm{MBF} /$ rest $\mathrm{MBF})$ value, as determined with ${ }^{82}$ Rubidium-PET/CT, in patients with and without ESLD undergoing either pharmacological vasodilation with dipyridamole or dobutaminestimulation. Patients were grouped into ESLD group undergoing ${ }^{82}$ Rubidium-PET/CT with dipyridamolestress $(n=27)$ or dobutamine-stimulation $(n=26)$, while twenty low-risk individuals without evidence of coronary calcifications served as control group with dipyridamole-stress. As it was observed, ESDL group with dipyridamole-stress had a lower myocardial flow reserve (MFR) than the control group $(1.89 \pm 0.79$ vs. $2.79 \pm 0.96 ; P<0.05)$, while the ESDL group with dobutamine-stimulation demonstrated significantly higher MFR values than both of these groups $(3.69 \pm 1.49)$. Further, there was a moderate negative correlation between clinical model for end-stage liver disease (MELD) score and left ventricular MFR among the ESDL dipyridamole-stress group $(r=0.47$, $P<0.05$ ), not observed for the ESDL dobutaminestimulation group $(r=0.25, P=0.21)$. Albeit that this inverses relationship is modest and based on low numbers, it signifies a progressive decrease in MFR with an increasing stage of ESDL. Such inverse relationship may outline yet unknown substances, released from the liver, to affect the MBF response to dipyridamole-stress. This contention is emphasized by the "paradoxical", higher increase in hyperemic MBFs and MFR during dobutamine-stimulation than during dipyridamolestress. Further, the striking difference between hyperemic MBFs is between ESDL with dipyridamole-stress (about $1.8 \mathrm{ml} / \mathrm{g} / \mathrm{minute}$ ) versus dobutamine-stimulation (about $2.8 \mathrm{ml} / \mathrm{g} / \mathrm{minute}$ ). This contrasts previous observations ${ }^{5}$ comparing the hyperemic MBF response of direct vasodilators such as adenosine or dipyridamole versus dobutamine-stimulation. Such observations raise indeed some concern about the use of vasodilator agents as appropriate stressor to induce hyperemic flow increases in ESLD patients. Someone could indeed argue that the difference in radiotracer uptake during hyperemic flows between regions subtended to obstructive, flow-limiting $\mathrm{CAD}$ lesions and remote regions may be relatively low or minimal to bring out meaningful perfusion deficits during dipyridamolestress. ${ }^{16}$ This could then indeed result in a lower sensitivity and diagnostic accuracy in CAD detection in patients with ESLD than in those without. While such considerations may be intuitively correct, further head- to-head PET perfusion-flow studies between dipyridamole-stress and dobutamine-stimulation in the detection of obstructive CAD are needed before more definite recommendations can be stated. Of further interest, the hyperemic MBF increase in the control group with dipyridamole-stress to increase hyperemic MBF was virtually the same as in the ESDL with the same stressor. The reason for this finding remains uncertain but likely is related to adverse effects of cardiovascular risk factors and yet unknown factors on microvascular function in the low-risk control group. ${ }^{17}$ Unfortunately, more detailed information of ${ }^{82} \mathrm{Rb}$-PET/ CT-determined MBFs during dipyridamole-stress or dobutamine-stimulation in healthy controls without known cardiovascular risk factors is missing, which would have provided an important framework of reference $\mathrm{MBF}$ values for the range of normal hyperemic MBFs and MFR. Taken together, the findings of the current investigation reported by Abele et al.. ${ }^{15}$ are unique because they raise an important clinical issue in the value of dipyridamole-stress with MPI for CAD detection and prognostication in ESLD patients. It may be indeed possible that in such patients dobutaminestimulation of hyperemic MBFs may indeed reflect a better pharmacologic stressor for the provocation of regional perfusion deficits and, thus, for CAD detection than dipyridamole-stress that, however, awaits further clinical testing.

\section{Disclosure}

The authors declare that they have no conflict of interest.

\section{References}

1. Hogan BJ, Gonsalkorala E, Heneghan MA. Evaluation of coronary artery disease in potential liver transplant recipients. Liver Transpl. 2017;23:386-95.

2. Sonny A, Kelly D, Hammel JP, Albeldawi M, Zein N, Cywinski JB. Predictors of poor outcome among older liver transplant recipients. Clin Transplant. 2015;29:197-203.

3. Duvall WL, Singhvi A, Tripathi N, Henzlova MJ. SPECT myocardial perfusion imaging in liver transplantation candidates. $\mathrm{J}$ Nucl Cardiol. 2018. https://doi.org/10.1007/s12350-018-1388-3.

4. Holmes AA, Phillips LM. Cardiopulmonary exercise testing and SPECT myocardial perfusion imaging: Pre-test probability is the key. J Nucl Cardiol. 2017. https://doi.org/10.1007/s12350-017-09 96-7.

5. Jagathesan R, Barnes E, Rosen SD, Foale RA, Camici PG. Comparison of myocardial blood flow and coronary flow reserve during dobutamine and adenosine stress: Implications for pharmacologic stress testing in coronary artery disease. J Nucl Cardiol. 2006;13:324-32.

6. Schindler TH, Zhang XL, Vincenti G, Lerch R, Schelbert HR. Role of PET in the evaluation and understanding of coronary physiology. J Nucl Cardiol. 2007;14:589-603. 
7. Valenta I, Quercioli A, Schindler TH. Diagnostic value of PETmeasured longitudinal flow gradient for the identification of coronary artery disease. JACC Cardiovasc Imaging. 2014;7(4):387-96.

8. Schindler TH, Schelbert HR, Quercioli A, Dilsizian V. Cardiac PET imaging for the detection and monitoring of coronary artery disease and microvascular health. JACC Cardiovasc Imaging. 2010;3:623-40.

9. Severi S, Underwood R, Mohiaddin RH, Boyd H, Paterni M, Camici PG. Dobutamine stress: effects on regional myocardial blood flow and wall motion. J Am Coll Cardiol. 1995;26:1187-95.

10. Krivokapich J, Czernin J, Schelbert HR. Dobutamine positron emission tomography: absolute quantitation of rest and dobutamine myocardial blood flow and correlation with cardiac work and percent diameter stenosis in patients with and without coronary artery disease. J Am Coll Cardiol. 1996;28:565-72.

11. Krivokapich J, Huang SC, Schelbert HR. Assessment of the effects of dobutamine on myocardial blood flow and oxidative metabolism in normal human subjects using nitrogen-13 ammonia and carbon-11 acetate. Am J Cardiol. 1993;71:1351-6.

12. Jagathesan R, Kaufmann PA, Rosen SD, Rimoldi OE, Turkeimer F, Foale R, et al. Assessment of the long-term reproducibility of baseline and dobutamine-induced myocardial blood flow in patients with stable coronary artery disease. J Nucl Med. 2005; 46:212-9.

13. Levine MG, Ahlberg AW, Mann A, White MP, McGill CC, Mendes de Leon C, et al. Comparison of exercise, dipyridamole, adenosine, and dobutamine stress with the use of Tc-99 m tetrofosmin tomographic imaging. J Nucl Cardiol. 1999;6:389-96.

14. Dorbala S, Ananthasubramaniam K, Armstrong IS, Chareonthaitawee P, DePuey EG, Einstein AJ, et al. Single Photon Emission Computed Tomography (SPECT) Myocardial Perfusion Imaging Guidelines: Instrumentation, Acquisition, Processing, and Interpretation. J Nucl Cardiol. 2018;25:1784-846.

15. Abele JT, Raubenheimer M, Bain VG, Wandzilak G, AlHulaimi $\mathrm{N}$, Coulden R, et al. Quantitative blood flow evaluation of vasodilation-stress compared with dobutamine-stress in patients with end-stage liver disease using ${ }^{82} \mathrm{Rb}$ PET/CT. J Nucl Cardiol 2018;2018 (in press).

16. Valenta I, Antoniou A, Marashdeh W, Leucker T, Kasper E, Jones SR, et al. PET-measured longitudinal flow gradient correlates with invasive fractional flow reserve in CAD patients. Eur Heart $\mathbf{J}$ Cardiovasc Imaging. 2017; 18:538-48.

17. Schindler TH. Myocardial blood flow: putting it into clinical perspective. J Nucl Cardiol. 2016;23:1056-71. 